\title{
Do Workgroup Faultlines Help or Hurt? A Moderated Model of Faultlines, Team Identification, and Group Performance
}

\author{
Katerina Bezrukova \\ Psychology Department, Santa Clara University, Santa Clara, California 95053, ybezrukov@ @scu.edu \\ Karen A. Jehn \\ Social and Organizational Psychology, Leiden University, Wassenaarseweg 52, 2333 AK Leiden, \\ The Netherlands, jehnka@fsw.leidenuniv.nl \\ Elaine L. Zanutto \\ National Analysts Worldwide, Philadelphia, Pennsylvania 19103, ezanutto@yahoo.com
}

Sherry M. B. Thatcher

Management and Entrepreneurship Department, University of Louisville, Louisville, Kentucky 40292, smthat01@louisville.edu

\begin{abstract}
Tn this study we examine a moderated model of group faultlines, team identification, and group performance outcomes. We extend research on faultlines by showing how different faultline bases (social category and information-based faultlines) may have differential effects on the performance of groups. In addition to faultline strength (the extent of demographic alignment across members within a group), we examine the distance between faultline-based subgroups (e.g., two members of age 20 are closer in age to two members of an opposing subgroup of age 25 than of two members of age 50). We test our model using an archival field methodology and multiple-source data (qualitative and quantitative) from 76 workgroups in a Fortune 500 information-processing company. Our results revealed that groups with social category faultlines had low team discretionary awards. Faultline distance further exacerbated the negative effects of strength in groups with social category faultlines and produced similarly negative effects in groups with information-based faultlines. Team identification served as a moderator enhancing performance of groups with information-based faultlines.
\end{abstract}

Key words: faultlines; performance; team identification; groups and teams

History: Published online in Articles in Advance August 8, 2008.

Driven by the growing popularity of groupwork and diversification of society at large, organizations are faced with the challenge of finding ways to reap the benefits of diversity while minimizing disruptions that are likely to arise in diverse groups. As businesses strive to reach multiple markets and remain competitive by taking advantage of groups whose members are different on multiple dimensions, the question of whether diversity helps or harms effectiveness becomes vital for both managers and researchers (cf. Jackson et al. 2003, Mannix and Neale 2005, Williams and O'Reilly 1998). Despite a rich history of research in this area, attempts to capitalize on diversity have met with mixed success, which suggests that a more comprehensive approach to the study of group diversity is needed. One of the most intriguing advances along these lines comes from the group faultline perspective introduced by Lau and Murnighan (1998). Departing from prior diversity research, faultline researchers propose to view the group makeup not only within a single-attribute perspective (e.g., group racial diversity) but also to think about people as a complex bundle of demographics; each person in a group belongs to many subgroups such as those defined by gender, race, education, and age (Gibson and Vermeulen 2003, Jehn et al. 2007, van Knippenberg and Schippers 2007).

Faultlines are defined as hypothetical dividing lines that split a group into relatively homogeneous subgroups based on the group members' demographic alignment along multiple ${ }^{1}$ attributes (adapted from Lau and Murnighan 1998). This partition provides the impetus for group members with different demographics to differentiate themselves and potentially fracture into competing subgroups within the group. For example, a clean-cut demographic alignment in a group (e.g., group members align such that all the men are young and all the women are middle-aged) may accentuate coalitions and ultimately result in salient subgroup identities (a subgroup of young men versus a subgroup of middle-aged women) (Cramton and Hinds 2005). In this study, we build on the tradition set by prior faultline research (e.g., Lau and Murnighan 2005, Thatcher et al. 2003) and focus on understanding how the alignment properties of group composition based on objective 
demographic attributes explain performance in face-toface colocated workgroups. This line of work assumes that individuals identify and act in ways consistent with a particular demographic grouping; that is, objective demographic differences explain variance in attitudes and behavior (cf. Williams and O'Reilly 1998). Thus, when we refer to faultlines and faultline subgroups, we are basing this on the objective demographic alignment of members (e.g., Lau and Murnighan 2005, Thatcher et al. 2003).

One of the recent criticisms of this work has been whether the faultline approach adequately takes into account the nature, or type, of member differences (e.g., Gibson and Vermeulen 2003). For instance, a faultline between two middle-aged females and two young males (i.e., a faultline based on age and gender; social categories) and a faultline between two experienced high school graduates and two just-hired Ph.D.s (i.e., a faultline based on level of education and work experience; information-based categories) may trigger quite different dynamics in a group, yet this distinction has often been overlooked. Prior work in this area has also been criticized because most theorizing about faultlines has focused on the concept of faultline strength (defined as the extent of demographic alignment across members within a group; Lau and Murnighan 1998); yet another important aspect of faultlines-differences or distance between the aligned subsets of members-has been generally ignored. However, differences can fluctuate from one subset to another (e.g., two members of age 20 are closer in age to two members of an opposing faultline subset of age 25 than to two members of age 50), and this faultline distance may have a unique effect on behavior. Thus, we introduce an extended faultline perspective that explains how social category and informational characteristics (Jehn et al. 1999) may serve as a basis for developing respective types of faultlines within a group and how faultline distance may explain additional variance in group performance.

As we extend our focus toward uncovering deeper mechanisms behind faultline dynamics, we also realize that various group and organizational factors may influence the relationships between group composition and performance. Thus, our third objective is to understand how team identification may influence faultline dynamics. For example, whether and how young male members in a group may act in terms of their gender- and agedefined categories will partly depend on how strongly they identify with their workgroup. In the present study, we consider the role of team identification to better understand when and how faultlines may affect group performance and what organizations can do to manage and use faultlines to their advantage. Team identification reflects a perception of oneness with, or belonging to, a team; it captures the extent to which a workteam is valued and contributes to a sense of self (Ashforth and Mael 1989). Although social identity research suggests that correlated demographic characteristics increase the likelihood of subgroups and reinforce existing category boundaries (Eurich-Fulcer and Schofield 1995), the strength of members' attachment to the group (team identification) may bind members together into a powerful psychological entity (Gaertner et al. 1993, Van der Vegt and Bunderson 2005). Therefore, our study also examines how team identification affects the relationships between faultlines and group performance outcomes.

\section{Extending the Group Faultline Framework}

Research on faultlines has contributed to the diversity literature by theorizing about the effects of group member characteristics in combination rather than separately. The faultline perspective claims that it is not the dispersion of certain demographic differences within a group, but rather their particular demographic alignments across group members, that influence behavior. When multiple demographic attributes align, differences across group members create a partition that may potentially cause a disruption in the group. Such demographic alignments have been shown to produce more direct and pervasive effects on group processes and outcomes than simple dispersion of member differences (Bezrukova et al. 2007, Lau and Murnighan 2005, Li and Hambrick 2005). However, there has been less consistency across studies when considering the directional effects of faultlines. Some studies have reported tension and low performance (e.g., Dyck and Starke 1999, Li and Hambrick 2005), whereas others have shown increased learning behavior and satisfaction (Gibson and Vermeulen 2003, Lau and Murnighan 2005). In summary, the goal of our research is to reconcile some of the controversies around faultlines by: (1) examining the different bases of faultlines (social category and information based), (2) taking into account two different dimensions of faultlines (faultline strength and distance), and (3) considering the effects of potential moderators in developing a more complete moderated model of the effects of faultlines on group performance.

\section{Faultline Bases: Social and Information-Based Categories}

Faultlines form when differences on one dimension produce notable schisms that are then coupled with schisms on other dimensions ( $\mathrm{Li}$ and Hambrick 2005). For example, such schisms could occur along social category (e.g., gender, age), or along information-based (e.g., education, work experience) attributes. These attributes vary in how relevant they are to the tasks performed by a group and in how much impact they may have on taskrelated employee behavior (Randel and Jaussi 2003). Researchers have suggested that the effects of diversity may depend on the degree of job relatedness of the 
attribute (Webber and Donahue 2001) and the potential for information use (Dahlin et al. 2005). Following Jehn and her colleagues (Jehn et al. 1997, 1999) who have stressed the value in differentiating between types of diversity, we argue that faultlines based on social categories and faultlines based on informational categories may have different implications for workgroups. Although some studies have looked at faultlines formed along social category characteristics (e.g., Earley and Mosakowski 2000, Lau and Murnighan 2005) or across a number of various attributes (e.g., Bezrukova et al. 2007, Gibson and Vermeulen 2003, Thatcher et al. 2003), little is known about how the nature of members' alignments (social category versus informational) may affect performance in diverse workgroups.

Social category faultlines are hypothetical dividing lines that split a group into subgroups based on members' alignment on social category demographic characteristics. Social category characteristics are attributes such as race/ethnic background, nationality, sex, and age (Cummings et al. 1993; Jehn et al. 1997, 1999). Whereas members' differences on these characteristics may not be directly relevant to a given task, they do shape people's perceptions and behaviors through mechanisms of categorization, stereotyping, and prejudice (Messick and Mackie 1989). On the other hand, information-based faultlines form when group members' multiple attributes come into alignment and split a group into relatively homogeneous subgroups based on informational characteristics. Informational characteristics are underlying attributes of individuals that are directly job related (such as work and education experiences) and are important in the completion of a task (Jackson et al. 2003; Jehn et al. 1997, 1999). Members' differences on these characteristics - the number of differences as well as the spread of information content and experience (e.g., graduating from the eighth grade versus having a Ph.D.) are typically associated with a broader array of relevant information and a larger pool of task-relevant skills that group members bring to a team (Jehn et al. 1997, 1999; Tsui et al. 1992; Webber and Donahue 2001; Williams and O'Reilly 1998).

Whereas Lau and Murninghan (1998) based the idea of faultlines on social identity, self-categorization, and coalition theories, we believe that a cognitive resource perspective should be added when conceptualizing information-based faultlines. A cognitive resource perspective suggests that diversity in job-related or informational characteristics offers greater cognitive resources to the group than do other types of diversity (Tziner and Eden 1985). For example, an extended resource pool may exist based on members' differences in knowledge and expertise, from which a member can draw to solve problems pertinent to the task at hand. Whereas social category faultlines are driven by social processes that may invoke social categorization and set in motion mechanisms such as stereotyping and prejudice, information-based faultlines are driven by informational processes that are more likely to work in accordance with a cognitive resource perspective. This informationbased perspective suggests increases in the flexibility of group members' thoughts (De Dreu and West 2001, Nemeth 1986) because it facilitates effective pooling of information and integrating of alternative perspectives (Gruenfeld et al. 1996). Information-based faultlines may operate in workgroups as "healthy divides" that stimulate effective decision-making processes and foster learning (Cramton and Hinds 2005, Gibson and Vermeulen 2003) by utilizing the teams' cognitive resources. We believe that the nature of members' alignments (social category versus information-based) may trigger different processes that will have different effects on group behavior.

\section{Faultline Distance}

The concept of "distance" in itself is not new to sociological, social psychological, or organizational behavior literatures. For instance, the social distance perspective (widely researched in sociology) suggests that group members share a schema that cognitively constructs outgroup members into a hierarchy by agreeing which groups are to be kept at a greater distance than others (Bogardus 1925, Rokeach 1960). Group members construct these social representations based on social distances that exist between members of one group and members of different groups defined by nationality, ethnicity, occupation, and other demographic attributes (e.g., Hraba et al. 1989). Similarly, research on multiform heterogeneity has introduced the concept of distance to describe how people make social distinctions in their associations with one another to differentiate role relations (Blau 1977). This body of literature suggests that the social distinctions implicit in assumptions about demographic characteristics reinforce one another, widen social barriers, and fragment society.

Cross-cultural research has utilized a related concept, cultural distance, which refers to subjective perceptions of differences between members of home and host cultures (Leong and Ward 2000). Of particular interest is the notion of a "gap" between cultures that involves clear contrasts and divisions (Tafarodi et al. 2002). The idea of cultural distance has received further development in contemporary literature on transnational teams and international joint ventures (IJV) (e.g., Earley and Mosakowski 2000, Hambrick et al. 2001, Salk and Shenkar 2001). In this line of research, cultural differences are posited to cause misunderstandings and performance problems in transnational and IJV teams (Li and Hambrick 2005, Polzer et al. 2006).

Social psychological research on cross-categorization has looked at the effects of group distinctiveness as conditional upon the relative distances between ingroups 
Table 1 Examples of Groups: Faultline Strength and Distance

\begin{tabular}{|c|c|c|c|c|c|c|c|}
\hline Group no. & Member A & Member B & Member C & Member D & $\begin{array}{l}\text { L\&M faultline } \\
\text { strength }^{a, b}\end{array}$ & $\begin{array}{l}\text { Strength } \\
\text { score }\end{array}$ & $\begin{array}{c}\text { Distance } \\
\text { score }\end{array}$ \\
\hline 1 & White male 21 & White male 21 & Black female 50 & Black female 50 & $\begin{array}{c}\text { Strong } \\
\text { (3 align, } 1 \text { way) }\end{array}$ & 1.00 & 3.49 \\
\hline 2 & Asian female 21 & White male 21 & Black female 25 & Asian male 35 & $\begin{array}{c}\text { Weak } \\
\text { (1 align, } 3 \text { ways })\end{array}$ & 0.40 & 1.25 \\
\hline 3 & White male 21 & White male 21 & Black female 25 & Black female 25 & $\begin{array}{c}\text { Strong } \\
\text { (3 align, } 1 \text { way) }\end{array}$ & 1.00 & 1.48 \\
\hline
\end{tabular}

aWith the number of identified attributes fixed at three, faultine strength, as defined by Lau and Murnighan (1998), is determined here by the number of demographic attributes that align (denoted as "align") and the possible ways to subdivide the group on the basis of these attributes (denoted as "ways").

${ }^{b}$ We use the following classification of faultline strength, based on the maximum number of characteristics that align: $1=$ weak, $2=$ medium, $3=$ strong.

and outgroups (Jetten et al. 1998). The basic assumption of cross-categorization is that overlapping memberships reduce the psychological distance between ingroups and outgroups. Large differences between subgroups may stand in the way of positive intersubgroup relations and widen the perceived gulf between "us" and "them" (Jetten et al. 2004). Some important insights about distance can also be found in the relational demography literature, which is, perhaps, of most relevance to our conceptualization of faultline distance. Within this tradition, studies have largely relied on the concept of demographic distance, or the degree of isolation of an individual from a group, which has been mostly found to be negatively associated with outcome variables (e.g., Tsui et al. 1992, Wagner et al. 1984).

Despite this previous research, early work on faultlines has primarily focused on the concept of faultline strength, which captures how many demographic attributes align within a group or, in other words, how cleanly a group may split into two fairly similar subgroups (e.g., Lau and Murnighan 1998, 2005; Thatcher et al. 2003). An example of a group with a strong faultline would be a fourperson group consisting of two white male employees who are 21 years old and two black female employees who are 50 years old (see Table 1, Group 1). In this group, the demographic alignment is clear because two homogeneous subgroups emerge based on group members' similarities in gender, race, and age; according to Lau and Murnighan (1998), there is a strong subgroup faultline. A four-person group consisting of one 21-year old Asian female, one 21-year old white male, one 25-year old black female, and one 35-year old Asian male would be an example of a group with weak faultline strength (see Table 1, Group 2). In this group, the demographic alignment across members is not as clear as in Group 1 and several subgroup possibilities exist; those based on gender, age, or race.

The faultline strength approach has not, however, adequately considered the extent to which subgroups diverge as a result of accumulated differences between subgroups-we label this aspect faultline distance. Consider a third group (Table 1, Group 3) that has the same faultline strength as Group 1, but a very different faultline distance: In this group, the two black females are 25 years old (rather than 50) and the two white males are 21 years old (see Table 1, comparing Groups 1 and 3). In Group 3, the two members of age 25 are closer in age to two members of the opposing subgroup (those of age 21) than the two members of age 50 in Group 1. Although both groups have a similar faultline strength (both characteristics align one way; per Lau and Murnighan 1998), we propose that the different distances between the subgroups will cause the effects of faultlines on performance outcomes in these groups to be very different. For example, an alignment of members (faultline strength) may induce awareness of membership into separate and distinct subgroups. However, faultline distance may moderate this relationship by escalating more antagonistic subgroup interactions in groups with large distances in which the members of one subgroup are extremely different from members of another subgroup. We believe that only when we consider the two aspects of faultlines simultaneously do we see the true effects of faultlines in diverse groups.

\section{A Moderated Model of Group Faultlines, Team Identification, and Group Performance}

Lau and Murnighan (1998) propose that faultlines are inherently detrimental because they promote processes such as potential conflict and communication problems. The alignment of demographic attributes based on the similarity of group members across social category characteristics (e.g., age and gender) is likely to amplify ingroup/outgroup distinctions and to sharpen the boundary salience around faultline subgroups. Social category membership provides a particularly salient basis for categorizing members into ingroups and outgroups (Jehn et al. 1999, Pelled et al. 1999). The negative effects of stereotyping, ingroup favoritism, and outgroup hostility can cause conflict and dislike to surface, and lead to decreased cohesion and social integration 
(Mackie et al. 2000, Tajfel and Turner 1986, Webber and Donahue 2001). The "us versus them" attitude that is likely to occur in groups with social category faultlines may facilitate fragmentation of groups and cause process loss and mismanagement ( $\mathrm{Li}$ and Hambrick 2005). For instance, cross-subgroup interactions and information exchanges that are necessary for accomplishing a task in common-goal groups will be limited in such groups (Lau and Murnighan 2005). Tension and personal attacks resulting from the categorization processes may also decrease efforts to share critical information in groups with social category faultlines (Sawyer et al. 2006). These processes are likely to adversely affect group performance.

HYPOTHESIS 1 (H1). Social category faultlines will be negatively associated with group performance.

We believe that work-related expectancy effects (Bettencourt et al. 1997) emerging from informationbased alignments (e.g., education, work experience) may have positive effects on group performance. Unlike social category characteristics, attributes that make up information-based faultlines have direct relevance to work, and play an important role in developing expectations about anticipated behaviors of others in the workplace. In groups with information-based faultlines, the fact that members across faultlines have different work experiences is consistent with the fact that they also may have different education levels. As group members become aware of their informational differences, they expect to be different along informational lines and may adopt an attitude of mutual positive distinctiveness (e.g., "We are different and that is ok") (Cramton and Hinds 2005). Because information-based differences directly contribute to the achievement of a common group goal (Jackson et al. 2003, Jehn et al. 1999, Pelled 1996, Webber and Donahue 2001), members of different informationally based subgroups may see the value in their differences and be able to effectively utilize all cognitive resources available to the group, thus increasing group performance. In addition, they may be more willing to engage in a thorough and intensive elaboration of the problem, freely express their ideas, and collaborate across faultline subgroups (Cramton and Hinds 2005, Gibson and Vermuelen 2003). A synthesis of ideas that is superior to any individual member idea may emerge (Schweiger and Sandberg 1989, Schwenk 1990) and reinforce group performance.

HYPOTHESIS 2 (H2). Information-based faultlines will be positively associated with group performance.

\section{Moderating Effects of Faultline Distance}

As previously discussed, the simple alignment of members along social category attributes induces awareness of membership into separate and distinct subgroups, and thus is likely to initiate unproductive interactions between subgroups. Faultline distance may further exacerbate this effect. First, a large distance encourages people to remain "psychologically located" within their subgroups and precludes them from exposing themselves to the ideas and behaviors of the larger group (Nesdale and Mak 2003). Second, member interactions across social category faultlines may become more antagonistic if members of one subgroup are extremely different from members of another subgroup (Jetten et al. 1998). Any disagreements across social category lines may be seen as wider, deeper, and more immutable as they are rooted in basic and fundamental beliefs (Miller and Prentice 1999). Such strained and unproductive interactions may further limit the extent to which valuable information is shared, used, and attended to in a group with social category faultlines. For instance, Wagner et al. (1984) found that larger demographic distances among the vicepresidents in 30 firms exacerbated the negative dynamics in top management teams. Chatman and Flynn (2001) demonstrated how respondents who were more demographically different were less effective performers and received less substantial compensation increases than those who were more similar to their colleagues. We therefore, propose that faultline distance will exacerbate the negative effects of social category faultlines in diverse groups.

Although work-based expectations may help members of groups with information-based faultlines capitalize on cognitive resources that such alignments bring to the group, these effects are contingent upon the extent to which subgroup members differ from each other. Strong and distant information-based faultlines may result in subgroup members speaking "different languages" and making it difficult to share tacit knowledge within a group (Weber and Camerer 2003). Because the amount of information and the access to the resource pool will be reduced in such groups (Clement and Schiereck 1973, Freidman and Podolny 1992), members of faultline subgroups may engage in coalition formation to provide support for their shared self-interest (Stevenson et al. 1985). Once a coalition is formed in a group, the implicit competition between coalition and noncoalition members may cause power differentiation and unequal distribution of resources within a team (Mannix 1993, Sherif 1966). Under these circumstances, members of faultline subgroups will be less inclined to make choices that would benefit their entire group, which may prompt severe losses in overall group performance. Thus,

Hypothesis 3A (H3A). Social category faultline distance will moderate the relationship between social category faultline strength and performance outcomes; that is, if there is a large distance between faultine-based subgroups, social category faultline strength is more likely to be associated with lower levels of group performance than if there is a small distance between them. 
HYPOTHESIS 3B (H3B). Information-based faultine distance will moderate the relationship between information-based faultine strength and performance outcomes; that is, if there is a large distance between faultline-based subgroups, information-based faultline strength is more likely to be associated with lower levels of group performance than if there is a small distance between them.

\section{Team Identification}

Individuals tend to pay particular attention to attributes that make them distinctive. For example, young females within a diverse group are more likely to describe themselves in terms of their gender and age when old male employees are present in a group (Roccas and Brewer 2002). They may define themselves as members of a "women's" subgroup (Brewer 1995, Tajfel and Turner 1986), but they may also perceive their entire workgroup as a unified entity and feel emotionally attached to their membership in this group. The extent to which they identify themselves with their workgroup as a whole can facilitate harmonious relations because the cognitive and motivational processes that produce positive feelings toward ingroups (Tajfel and Turner 1986) can now be extended toward outgroups (Mottolla et al. 1997). When members perceive themselves as sharing a common ingroup identity, the chances of subgroup categorization, identification, and associated biases are minimized (Gaertner et al. 1993, Gaertner and Dovidio 2000). That is, when members of one subgroup formed by a social category or information-based faultline perceive themselves to share a group membership with members of another subgroup (i.e., the overall workgroup), they are motivated to strive actively to reach agreement and coordinate their behaviors in identifying shared beliefs, clarifying points of agreement, and exchanging information (Haslam and Ellemers 2005, Hogg and Terry 2000, Pratt 1998). This team identification may act as some kind of "social glue" in preserving group integrity when the group is under the threat of a split (Kane et al. 2005, Van Vugt and Hart 2004).

Given that members may identify with multiple units of affiliation (Brewer 1995, Randel 2002), crosscategorization theory (Brewer 2000, Crisp and Hewstone 2000) provides additional support for the moderating effect of team identification. Cross-categorization is based on cross-cutting categories within groups, where "others" can be simultaneously classified as ingroup or outgroup members based on multiple dimensions (Hewstone et al. 2002). Subgroup and team memberships can be viewed as a special sort of crossed categorization, with the shared group category (e.g., the workgroup) at a more inclusive level of the category hierarchy (Hornsey and Hogg 2000). The strength of team identity, which cuts across demographically aligned subgroup members, places members' emphasis on similarities across subgroups (Brewer 2000). Cross-cutting identification further decreases bias and contributes to productive intersubgroup contact by reducing psychological distance between distant subgroups (Crisp and Hewstone 2000, Hornsey and Hogg 2000) emerging from a social category or information-based faultline. The former intersubgroup boundaries become less salient, and instead, new, inclusive team-based boundaries become important in the minds of members. This logic suggests that team identification may reverse the negative effects associated with faultline distance in groups with social category or information-based faultlines. Therefore, we propose:

Hypothesis 4A (H4A). A three-way interaction between social category faultine strength, distance, and team identification is expected, such that groups with strong and distant faultlines and high levels of team identification are likely to have higher levels of group performance than groups with low levels of team identification.

Hypothesis 4B (H4B). A three-way interaction between information-based faultline strength, distance, and team identification is expected, such that groups with strong and distant faultlines and high levels of team identification are likely to have higher levels of group performance than groups with low levels of team identification.

\section{Method}

\section{Research Site and Sample}

Our study population is a Fortune 500 organization that specializes in mailing and document processes and technologies that save customers' time and money and enhances their security. Data were collected in 1999 as part of a broader research study on the effects of diversity. Archival data on the groups came from two company data sources: corporate databases (e.g., demographic information; team member listings; performance) and company text documents from human resource programs (e.g., workgroup development reports).

We identified the workgroups in our data set using managers' names and a reporting system developed by the company. We verified that these were actual working groups in existence for over a year (they identified each other as group members and were seen by others as workgroups, Hackman 1987) by interview and observation. Key senior staff and employees also informed us that group members did not select themselves but rather were assigned to the teams and that "groups" of one or two employees or groups with over sixteen employees were not actual working groups. The latter is consistent with the definition of a group (see above) and with group process theories regarding group size (e.g., Goodman et al. 1986). Therefore, the effective sample size was 
567 individuals (76 groups). All teams were management groups who had certain nonroutine task characteristics (the task is complex and not well understood, it has a few set procedures, and a high level of variability, Van de Ven et al. 1976). Employees' average age and organizational tenure were 48 and 14 years, respectively. Roughly $70 \%$ were male and $60 \%$ had some college education.

\section{Measures}

Group Faultlines. Our methodology for measuring faultlines was motivated by Lau and Murnighan's (1998) faultline framework in estimating how the alignment of multiple demographic attributes can potentially subdivide a group. We adapted our faultline measures from the multivariate statistical clustering analysis literature (e.g., Jobson 1992, Morrison 1967, Sharma 1996), which provides statistics for estimating how well the variability within the group can be explained by the presence of different clusters within the group. We measured social category and information-based faultlines along two social category characteristics (gender and age) and two informational characteristics (level of education and tenure). These demographic variables were chosen based on availability in the data set and previous research on group diversity (Jehn et al. 1997, 1999; Tsui et al. 1992).

To measure faultline strength, we relied on the faultline algorithm developed by Thatcher et al. (2003) and used in faultline research by others (e.g., Lau and Murnighan 2005, Molleman 2005). This algorithm calculates the percent of total variation in overall group characteristics accounted for by the strongest group split by calculating the ratio of the between-group sum of squares to the total sum of squares (faultline strength can take on values between zero and one, with larger values indicating greater strength). Possible values of faultline strength ranged from 0.386 to 0.954 for social category faultlines and from 0.398 to 0.936 for information-based faultlines in our data set.

We extend prior operationalizations of group faultlines by measuring faultline distance along the strongest faultline split (our faultline measure includes one score for strength, one score for distance). Faultline distance reflects the extent to which subgroups formed across faultlines diverge, or in other words, how far apart they are from each other on social category and informational characteristics. The faultline distance measure was adapted from multivariate statistical cluster analysis (e.g., Jobson 1992, Morrison 1967, Sharma 1996) and was calculated as a distance between the faultline variable centroids for the subgroups (the Euclidean distance between the two sets of averages):

$$
D_{g}=\sqrt{\sum_{j=1}^{P}\left(\bar{X}_{1 j^{\cdot}}-\bar{X}_{2 j^{\prime}}\right)^{2}},
$$

where the centroid (vector of means of each variable) for subgroup $1=\bar{X}_{11}, \bar{X}_{12}, \bar{X}_{13}, \ldots, \bar{X}_{1 P}$. and the centroid for subgroup $2=\bar{X}_{21}, \bar{X}_{22}, \bar{X}_{23}, \ldots, \bar{X}_{2 P}$. Faultline distance can take on values between zero and $\infty$, with larger values indicating a larger distance between faultline subgroups. Values of faultline distance ranged from 0.54 to 3.02 for social category faultlines and from 0.43 to 2.90 for information-based faultlines in our data set (see Table 1 for examples of groups with varying levels of faultline strength and distance, and Table 2 for means and standard deviations of faultline strength and distance in this study).

Group Performance. We measured group performance using two variables; team discretionary awards (company's archival data) and perceived performance (content-analyzed company documents). Teams were formally recognized for team discretionary awards based on team performance. These awards were granted once a year based on discretionary award recommendations provided by the senior management through a grant nomination process. Because awards were given in various forms (e.g., lump-sum merit, special bonus, option shares, etc.), we averaged the standardized values on various award variables to arrive at our overall team discretionary awards measure.

Perceived team performance was assessed through content coding of 300 pages of documents that were part of the company's human resource program. In our qualitative methodology, we adapted the procedure developed by Chatman and Flynn (2001) in their content analysis of team evaluation papers. Employees completed development reports regarding their workgroups as a method for improving planning and determining what employees think about their team's performance. The data were responses to an open-ended question that asked them to identify the key issues for their groups in dealing with performance gaps (if any) and to set action priorities. Following the procedure of Doucet and Jehn (1997), we developed lists of key words characterizing our performance variable based on relevant group and organizational theories (e.g., Hackman 1987), as well as the concepts used in the company's rhetoric. We conducted computer-aided text analysis on the company's textual data using the program MonoConc Pro 2.0 (Barlow 2000) and created frequency lists with the terms mentioned most, to least, often. To arrive at the keyword list for this variable, two raters first independently considered all terms from the frequency lists and selected the key words representing this variable (interrater agreement $=0.92$ ). Examples of key terms included words such as "best-of-breed," "progress," "success," "efficient," "effective," "gain," and "improved" (e.g., Chatman and Flynn 2001) following the key-word snowball technique of Jehn and Werner (1993).

Based on the method of Jehn and Werner (1993), two independent raters further conducted the key-word 
searches on all individual responses, reviewed the surrounding context, and coded the text for perceived team performance. The raters followed guiding questions based on past research (Chatman and Flynn 2001; e.g., "To what extent does a group accomplish its purpose and produce the intended, expected, and desired result?") and rated each individual response on a scale from 1 (the least) to 7 (the most). When raters assigned the score farther than one point apart, they discussed an issue until they reached an agreement. The variablespecific Cohen's Kappa was 0.74, and on the basis of these results, we concluded that our coding was reliable. We further assessed whether analyzing this dependent variable at the group level was justified by calculating eta-squared statistic $\varepsilon^{2}$, which indicates whether any two people in the same group are more similar than two people of different groups (Florin et al. 1990, Jehn et al. 1999). The eta-squared statistic for this variable was 0.58 , which exceeded the minimum criterion of 0.20 and indicated that there was less variance in group members' responses than was expected by chance. In addition, we performed intraclass correlation coefficient (ICC[1]) analysis to estimate the proportion of variance in the variable between groups over the sum of between- and within-group variance (Bliese 2000). The 0.74 value of ICC[1] was significant at $p<0.001$ and confirmed that analyzing this dependent variable at the group level was justified.

Team Identification. In our measurement approach, we first drew on the common ingroup identity model (Gaertner et al. 1993) and operationalized team identification as participants' superordinate group representations (or the sense of "we-ness") (Dovidio et al. $1997 \mathrm{a}, \mathrm{b})$. We then built on qualitative work in the area of organizational identity and identification (e.g., Brickson 2005, Earley and Mosakowski 2000, Pratt 2000) to arrive at our measure of team identification. A different set of raters coded the company's documents for team identification using the key words and reviewing the surrounding context as described above. Examples of key terms for team identification included words such as "identification," "dedicated," "together," "support," "our," and "involved" (interrater agreement $=0.89$ ) taken from key theoretical articles and survey items (Mael and Ashforth 1992, Mottola et al. 1997, van Knippenberg and Ellemers 2003), and verified by qualitative work in the area of organizational identity and identification (Earley and Mosakowski 2000). The raters followed guiding questions based on past research (Kane et al. 2005, Mullin and Hogg 1998; e.g., "To what extent does the group member identify with the team?") and rated each individual response on a scale from 1 (the least) to 7 (the most). The 0.63 value of variable-specific Cohen's Kappa confirmed that our coding was reliable. We further checked for within-group agreement to assess that all members identified with their team. The eta-squared statistic for this variable was 0.35 , and the 0.50 value of ICC[1] was significant at the 0.001 level. On the basis of these results, we confirmed that this variable represents a group-level construct and concluded that aggregation was justified.

Control Variables. In selecting our control variables, we focused on the variables that were available in our data set that have been shown to influence performance outcomes in past diversity research, and that could be viewed as alternative explanations for performance effects. First, we controlled for job level (e.g., assistant to CEO) because it normally accounts for the variation in the type of work and merit raises based on an employee's position within the job range (Chatman and Spataro 2005, Elvira and Graham 2003). We included job level as a continuous variable based on the company's assigned values, which ranged from 24 to 40 in our sample $(x=36.62$, s.d. $=2.43)$; 24 represents the lowest level of job and 40 represents the highest level of job. To control for diversity effects, we used Blau's (1977) heterogeneity index to measure group heterogeneity for categorical variables (e.g., gender) calculated as $H=-\sum P_{i}^{2}$, where $P$ represents the fractional share of team members assigned to a particular grouping within a given characteristic and $i$ is the number of different categories represented on a team. We used the coefficient of variation to measure group diversity for continuous variables (e.g., age) (Allison 1978). Following the procedure suggested by Jehn and her colleagues (1999) and widely used in recent diversity research (e.g., Polzer et al. 2002), we averaged age and gender heterogeneity variables to arrive at our social category heterogeneity control variable and averaged tenure and education heterogeneity variables to arrive at our informational heterogeneity control variable. These demographic characteristics were chosen based on previous diversity research (Williams and O'Reilly 1998), availability in the data set, and their respective match with our faultline variables.

\section{Results}

Table 2 displays means, standard deviations, and correlations among all variables. We examine the relationships between group faultlines, team identification, and performance outcomes using hierarchical regression analysis.

\section{Main and Moderating Effects of Faultline Strength and Distance}

Table 3 (see Model 1) shows the results of the hierarchical regression analysis testing the main effects of faultline strength. Step 1 of the hierarchical regression contained controls, including job level and heterogeneity variables. Step 2 included the main effects of either social category faultline strength or informational faultline strength. Step 3 included two-way interactions 
Table 2 Means, Standard Deviations, and Zero-Order Correlations Among Variables

\begin{tabular}{|c|c|c|c|c|c|c|c|c|c|c|c|}
\hline Correlations & $\begin{array}{c}\text { Mean } \\
(N=76)\end{array}$ & $\begin{array}{c}\text { S.D. } \\
(N=76)\end{array}$ & 1 & 2 & 3 & 4 & 5 & 6 & 7 & 8 & 9 \\
\hline $\begin{array}{l}\text { 1. Social category } \\
\text { faultline strength }\end{array}$ & 0.66 & 0.13 & & & & & & & & & \\
\hline $\begin{array}{l}\text { 2. Social category } \\
\text { faultline distance }\end{array}$ & 1.61 & 0.53 & $0.49^{* *}$ & & & & & & & & \\
\hline $\begin{array}{l}\text { 3. Information-based } \\
\text { faultline strength }\end{array}$ & 0.60 & 0.12 & -0.05 & -0.08 & & & & & & & \\
\hline $\begin{array}{l}\text { 4. Information-based } \\
\text { faultline distance }\end{array}$ & 1.68 & 0.50 & -0.03 & -0.02 & $0.30 * *$ & & & & & & \\
\hline $\begin{array}{l}\text { 5. Team discretionary } \\
\text { awards }\end{array}$ & 0.91 & 1.01 & -0.12 & -0.04 & -0.04 & 0.22 & & & & & \\
\hline $\begin{array}{l}\text { 6. Perceived team } \\
\text { performance }\end{array}$ & 3.98 & 0.79 & -0.09 & -0.11 & 0.04 & 0.11 & 0.06 & & & & \\
\hline 7. Team identification & 4.35 & 1.25 & -0.08 & -0.18 & 0.04 & 0.09 & -0.03 & $0.44^{* *}$ & & & \\
\hline $\begin{array}{l}\text { 8. Social category } \\
\text { heterogeneity }\end{array}$ & 0.23 & 0.09 & -0.09 & $0.41^{* *}$ & 0.04 & -0.10 & 0.01 & 0.02 & -0.11 & & \\
\hline $\begin{array}{l}\text { 9. Informational } \\
\text { heterogeneity }\end{array}$ & 0.41 & 0.12 & 0.11 & 0.09 & 0.06 & $0.60^{* *}$ & 0.12 & 0.15 & 0.07 & 0.04 & \\
\hline 10. Job level & 36.24 & 1.83 & 0.01 & 0.08 & -0.21 & 0.24 & $0.63^{* *}$ & -0.10 & -0.12 & -0.18 & 0.13 \\
\hline
\end{tabular}

${ }^{*} p<0.05 ;{ }^{* *} p<0.01$

(e.g., faultline strength $\times$ faultline distance). All variables were grand mean centered. Hypothesis 1 (H1) predicted that social category faultline strength would be negatively associated with group performance. In partial support of $\mathrm{H} 1$, social category faultline strength was negatively related to team discretionary awards $($ Beta $=$ $-0.17, p<0.05)$. The change in $R^{2}$ from steps 1 to 2 for the main-effect model indicated a significant increase above and beyond the control variables.

Hypothesis 3A (H3A) predicted that social category faultline distance will moderate the relationship between social category faultline strength and group performance; that is, if there is a large distance between faultline-based subgroups, strength is more likely to be associated with lower levels of group performance than if there is a small distance between subgroups. In full support of H3A (see Table 3, Model 2), social category faultline distance moderated the effects of faultline strength on team discretionary awards $($ Beta $=$ $-0.17, p<0.05)$ and perceived team performance $($ Beta $=-0.24, p<0.05)$. Hypothesis 3B $(\mathrm{H} 3 \mathrm{~B})$ stated that information-based faultline distance will moderate the relationship between information-based faultline strength and group performance; that is, if there is a large distance between faultline-based subgroups, strength is more likely to be associated with lower levels of group performance than if there is a small distance between subgroups. Supporting H3B, information-based faultline distance moderated the effects of faultline strength on team discretionary awards $($ Beta $=-0.25$, $p<0.05)$ and perceived team performance (Beta $=$ $-0.26, p<0.05)$. The change in $R^{2}$ from steps 2 to 3 for the moderated models indicated significant increases above and beyond the control and main-effect variables for all of the four effects. Graphing the relationship reflected that groups with strong (high faultline strength) and wide (high faultline distance) faultlines had lower levels of group performance than groups with low distances along the strongest splits (see Figure 1).

\section{Effects of Team Identification}

We conducted a series of hierarchical regression analyses to test Hypotheses 4A (H4A) and 4B (H4B) predicting three-way interactions between faultline strength, distance, and team identification, such that groups with strong and distant faultlines and high levels of team identification are likely to have higher levels of group performance than groups with low levels of team identification (see Table 3, Model 3). Step 1 of the hierarchical regression contained controls including job level and heterogeneity variables. Step 2 included all the main effects, step 3 included all the two-way interactions, and step 4 included a three-way interaction (e.g., informational faultline strength $\times$ distance $\times$ identification). Although H4A was not supported, H4B received full support. There were two significant three-way interactions between information-based faultline strength, distance, and team identification on group performance: team discretionary awards $($ Beta $=0.55, p<0.01)$ and perceived team performance $($ Beta $=0.46, p<0.05)$. The change in $R^{2}$ from steps 3 to 4 for the double moderated models indicated significant increases above and beyond the control and main-effect variables for informational faultlines effects. Graphing these relationships shows that groups with strong (high faultline strength) and wide (high faultline distance) faultlines and high levels of team identification had higher levels of group performance than groups with low levels of team identification (see Figure 2). 
Table 3 Hypothesis Testing Using Hierarchical Regression Analysis

\begin{tabular}{|c|c|c|c|c|c|c|}
\hline & \multicolumn{3}{|c|}{ Team discretionary awards } & \multicolumn{3}{|c|}{ Perceived team performance } \\
\hline & $\begin{array}{l}\text { Model } 1 \\
(\mathrm{H} 1)\end{array}$ & $\begin{array}{l}\text { Model } 2 \\
(\mathrm{H} 3)\end{array}$ & $\begin{array}{l}\text { Model } 3 \\
(\mathrm{H} 4)\end{array}$ & $\begin{array}{l}\text { Model } 1 \\
(\mathrm{H} 1)\end{array}$ & $\begin{array}{l}\text { Model } 2 \\
(\mathrm{H} 3)\end{array}$ & $\begin{array}{c}\text { Model } 3 \\
(\mathrm{H} 4)\end{array}$ \\
\hline \multicolumn{7}{|c|}{ Social category faultlines } \\
\hline Job level & $0.68^{* * *}$ & $0.68^{* * *}$ & $0.67^{* * *}$ & 0.03 & -0.01 & -0.02 \\
\hline $\begin{array}{r}\text { Social category } \\
\text { heterogeneity }\end{array}$ & -0.05 & -0.02 & -0.03 & 0.01 & 0.09 & 0.12 \\
\hline Fau strength (FS) & $-0.17^{*}$ & $-0.19^{*}$ & $-0.16^{\dagger}$ & -0.09 & -0.08 & -0.05 \\
\hline Fau distance (FD) & & -0.05 & -0.05 & & -0.06 & -0.02 \\
\hline Identification (I) & & & 0.03 & & & $0.41^{* * *}$ \\
\hline $\mathrm{FS} \times \mathrm{FD}$ & & $-0.17^{*}$ & $-0.16^{\dagger}$ & & $-0.24^{*}$ & $-0.25^{*}$ \\
\hline $\mathrm{FS} \times \mathrm{I}$ & & & $0.18^{*}$ & & & 0.08 \\
\hline $\mathrm{FD} \times 1$ & & & 0.04 & & & -0.13 \\
\hline $\mathrm{FS} \times \mathrm{FD} \times 1$ & & & 0.03 & & & 0.05 \\
\hline Change in $R^{2}$ & 0.03 & 0.03 & 0.00 & 0.01 & 0.05 & 0.01 \\
\hline$F$ change & $1.87^{*}$ & $1.36^{*}$ & 0.27 & 0.52 & $3.81^{*}$ & 0.12 \\
\hline$R^{2}$ & 0.48 & 0.48 & 0.43 & 0.01 & 0.07 & 0.26 \\
\hline Adjusted $R^{2}$ & 0.47 & 0.48 & 0.33 & 0.01 & 0.01 & 0.16 \\
\hline \multirow[t]{2}{*}{$F$} & $13.86^{* * *}$ & $8.51^{* * *}$ & $4.24^{* * *}$ & 0.21 & $1.02^{*}$ & $2.59 *$ \\
\hline & $\begin{array}{l}\text { Model } 1 \\
(\mathrm{H} 2)\end{array}$ & $\begin{array}{c}\text { Model } 2 \\
(\mathrm{H} 3)\end{array}$ & $\begin{array}{c}\text { Model } 3 \\
(\mathrm{H} 4)\end{array}$ & $\begin{array}{c}\text { Model } 1 \\
(\mathrm{H} 2)\end{array}$ & $\begin{array}{c}\text { Model } 2 \\
(\mathrm{H} 3)\end{array}$ & $\begin{array}{c}\text { Model } 3 \\
(\mathrm{H} 4)\end{array}$ \\
\hline \multicolumn{7}{|c|}{ Information-based faultlines } \\
\hline Job level & $0.62^{* * *}$ & $0.59^{* * *}$ & $0.53^{* * *}$ & 0.02 & -0.02 & -0.03 \\
\hline $\begin{array}{l}\text { Informational } \\
\text { heterogeneity }\end{array}$ & 0.10 & 0.03 & 0.11 & 0.06 & 0.01 & 0.14 \\
\hline Fau strength (FS) & 0.06 & -0.05 & 0.07 & 0.03 & -0.08 & 0.09 \\
\hline Fau distance (FD) & & 0.14 & -0.02 & & 0.13 & -0.03 \\
\hline Identification (I) & & & -0.17 & & & $0.42^{* *}$ \\
\hline$F S \times F D$ & & $-0.25^{*}$ & -0.08 & & $-0.26^{*}$ & $-0.23^{*}$ \\
\hline $\mathrm{FS} \times \mathrm{I}$ & & & $0.57^{* *}$ & & & $0.44^{*}$ \\
\hline $\mathrm{FD} \times \mathrm{I}$ & & & $-0.22^{\dagger}$ & & & 0.16 \\
\hline $\mathrm{FS} \times \mathrm{FD} \times 1$ & & & $0.55^{* *}$ & & & $0.46^{*}$ \\
\hline Change in $R^{2}$ & 0.01 & 0.06 & 0.07 & 0.01 & 0.06 & 0.06 \\
\hline$F$ change & 0.27 & $5.79^{*}$ & $7.52^{* *}$ & 0.08 & $3.30^{*}$ & $5.23^{*}$ \\
\hline$R^{2}$ & 0.40 & 0.47 & 0.56 & 0.02 & 0.08 & 0.30 \\
\hline Adjusted $R^{2}$ & 0.37 & 0.43 & 0.48 & 0.00 & 0.01 & 0.20 \\
\hline$F$ & $12.65^{* * *}$ & $9.73^{* * *}$ & $7.14^{* * *}$ & 0.55 & $1.57^{*}$ & $3.09 * *$ \\
\hline
\end{tabular}

\section{Discussion}

The faultline framework is based on an intuitively powerful idea of group splits being inherently conflictual and detrimental, yet recent empirical findings in this area have been relatively inconsistent; groups with faultlines can suffer (e.g., Earley and Mosakowski 2000, Dyck and Starke 1999, Li and Hambrick 2005) as well as benefit from faultlines (Gibson and Vermeulen 2003, Hart and Van Vugt 2006, Lau and Murnighan 2005). In this study, we examined how different faultline bases (social category and information-based faultlines) may have different effects on group outcomes. Consistent with Lau and Murnighan's (1998) model of faultlines and intragroup processes, we found that the strength of social category faultlines was negatively associated with group performance. However, there was no evidence that information-based faultlines were negatively associated with performance. Although providing sup- port for the disruptive effects of social category alignments, our findings also suggest that not all faultline compositions are necessarily negative for group performance (especially when there is a high level of team identification). We also found that heterogeneity had no significant effects, which is not surprising given prior diversity research that showed that differences alone may not strongly impact ongoing work groups (e.g., Ely and Thomas 2001, Watson et al. 1993).

Our conceptualization of group faultlines as both (1) the extent of members' demographic alignment, and (2) the degree of distance between subgroups, enables us to make another contribution to faultline research. In our theorizing about these two properties of faultlines, we predicted that faultline distance would work as a theoretically distinct source of demarcation that moderates the effects of faultline strength in diverse groups. We found that faultline distance further exacerbated the negative 
Figure 1 Interactions: Moderated Effect of Distance
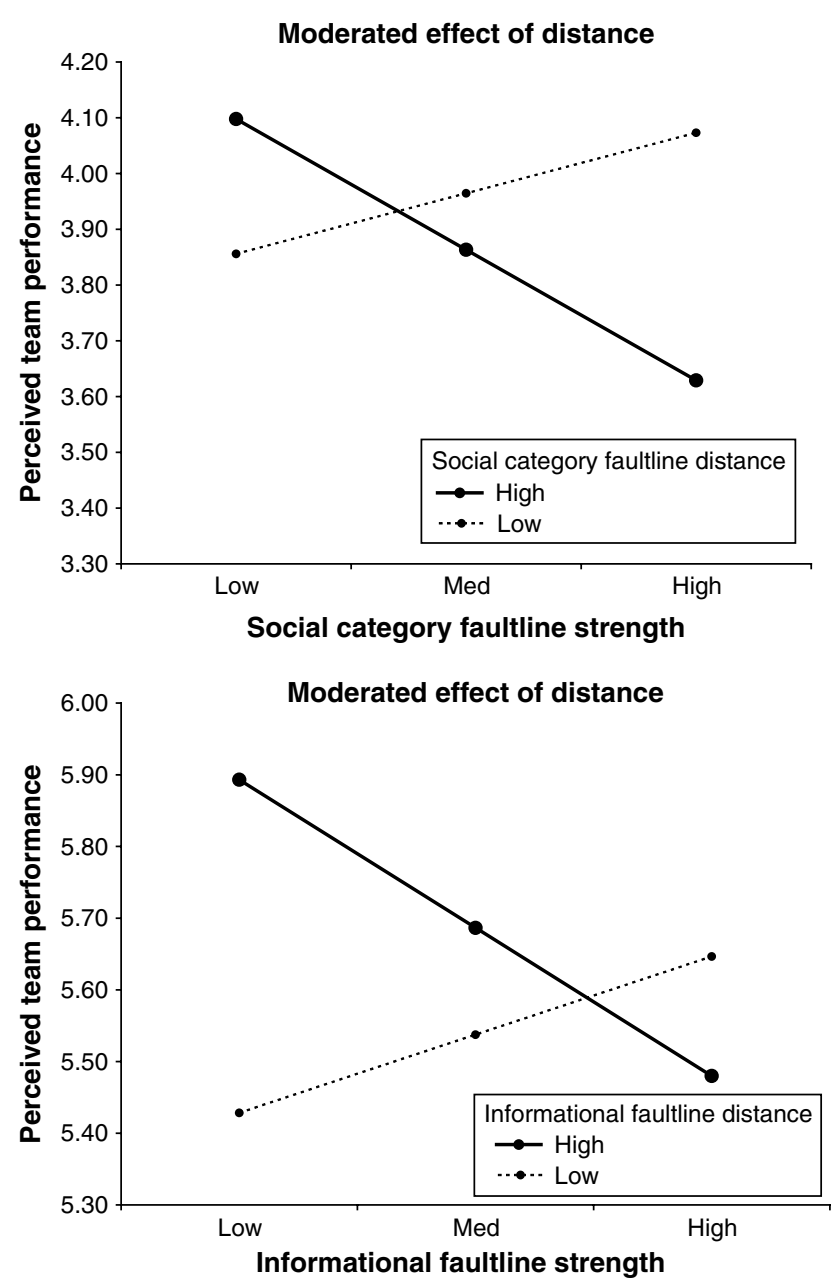

Notes. Low and high values represent one standard deviation below the mean and one standard deviation above the mean. Analysis is based on centered values (cf. Aiken and West 1991). The graphs of the interactions where team discretionary awards is the dependent variable resulted in similar shapes.

effects of social category faultline strength and produced similarly negative effects in groups with informationbased faultlines. It is possible to think that faultline distance may trigger additional negative categorization effects, potentially resulting in stereotyping and bias in groups with either faultline base (social category or informational). Faultline strength serves as a foundation for a faultline to exist and has a primary function, whereas distance truly shows itself as a moderator by exacerbating the effect of strength (which is evidenced by the significant interaction terms (see Table 3 )). For instance, strength may cause damage in groups with social category faultlines, but it may also promote healthy competition, stimulate information elaboration, and be beneficial for the groups with information-based faultline (Gibson and Vermeulen 2003, Phillips 2003, Rink and Ellemers 2007). However, when the distance
Figure 2 Interactions with Team Identification
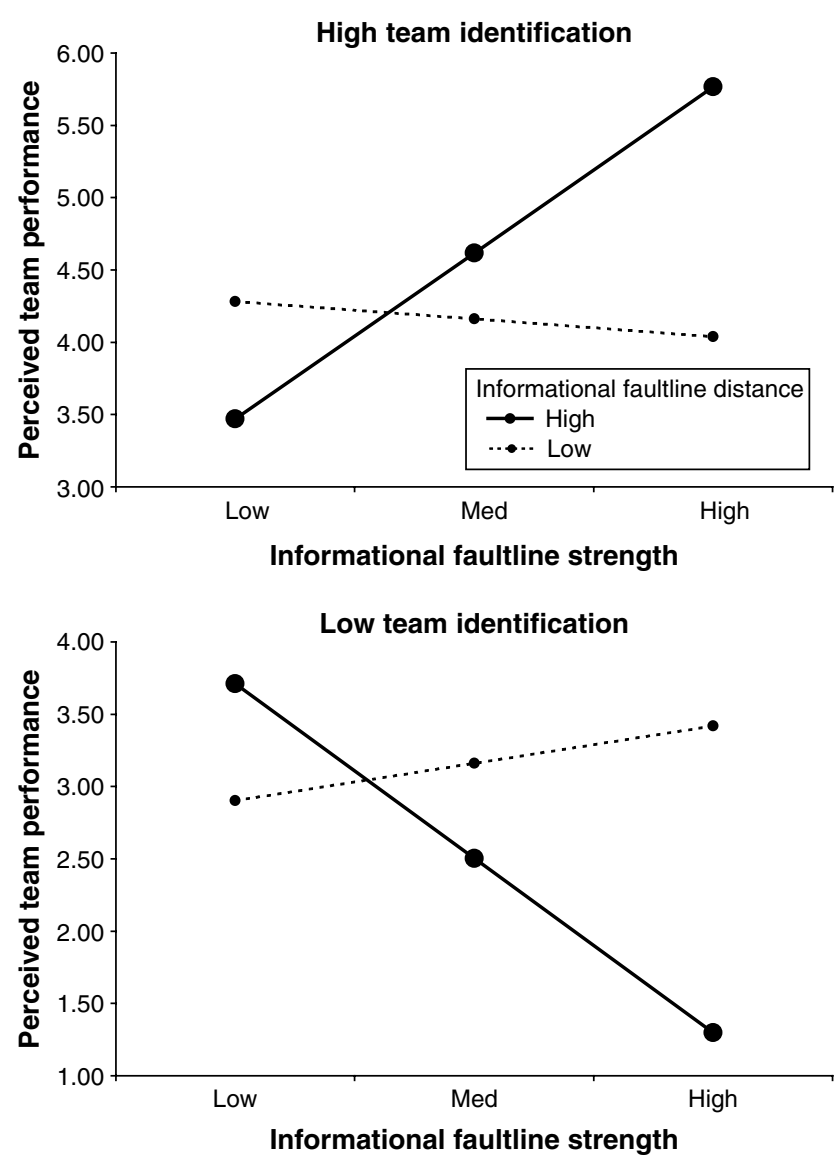

Note. The graphs of the interactions where team discretionary awards is the dependent variable resulted in similar shapes.

between faultline subgroups is large, potentially positive effects of faultline strength may be overruled by the processes such as implicit competition, communication breakdowns, and power differentials. Interestingly, we found that the performance of groups with low faultline strength varied depending on the distance; low strength groups had higher levels of performance when the distance was large than when it was small (see Figure 1). To understand this effect, we conducted supplementary analysis and found that "low diversity" groups (see Groups 2-4, Lau and Murnighan 1998) had low strength and low distance in our sample, whereas "high diversity" groups (see Groups 7 and 8, Lau and Murnighan 1998) had low strength and high distance. Although we did not predict this difference, the form of the interaction is consistent with theory; diverse groups with weak faultlines may have more potential for performance gains than do homogeneous groups on nonroutine tasks (Lau and Murnighan 1998).

Finally, we found that the extent to which group members identify with their workgroups played a critical role in how group faultlines translated into performance outcomes. When members strongly identified with their 
teams, groups with strong information-based faultines had high levels of performance. These results support the basic notion that faultlines are highly context dependent and might be beneficial under the "right" conditions (Williams and O'Reilly 1998). Taken together, our results show that while faultline distance may aggravate group functioning, the strength of members' identification with a team may alter this relationship and instead, enhance the group's performance, or at least lessen the negative effects. These findings are consistent with the common ingroup identity model (CIIM; e.g., Gaertner et al. 1993), which posits that bias reduction may occur when group members recategorize their perceptions of group boundaries to perceive themselves as sharing common ingroup identity. Interestingly, the significant effects were only observed for groups with information-based faultlines. One explanation is that when team identity is salient, groups may directly benefit from informational faultlines simply because informational differences have a more explicit connection with task performance than do social category differences. Team identification may assist these groups in avoiding potential performance losses by preserving group integrity via the united group feeling toward a common goal. It may help group members extend their focus toward recognizing the value of informational differences across faultline subgroups. When this happens, group members are more likely to exert greater effort on behalf of the group rather than spending time on reconciling the differences between subgroup members.

Our methodological contribution to existing research on group composition and faultlines comes in the form of devising a more accurate measure of the faultline construct. We theoretically justify the reason for considering faultline distance as an indicator of faultline "width" and empirically show the necessity of using the interaction between faultline strength and faultline distance. Our faultline distance measure provides valuable information that may add to our understanding of the effects of "rifts" between people in diverse groups and advance faultline research.

\section{Limitations of the Study and Future Directions}

The strengths of the current research (e.g., data collected from an actual workplace setting) are accompanied by potential weaknesses. Some limitations of this study are common in demography studies that use archival file data. First, although we were able to construct reliable measures of team identification and perceived team performance variables using content analysis of company documents, no direct survey measures were available. Future research should use employee survey data and interviews, if possible, to more fully understand how team identification and other context variables shape the effects of group faultlines. Next, as is typical in any archival study, our results are limited because of an omitted variable bias. For example, it is not possible to rule out all of the possible confounds as a number of factors in addition to our controls, faultline strength, faultline distance, and their interactions may predict group performance outcomes (e.g., individual ability, motivation and opportunity to perform, task interdependence). Furthermore, team identification could be a dependent variable and status, success, and performance may add to social identification with a group. Although our study design, as is common in field research, does not allow us to determine true cause-effect relationships, we believe that our model is feasible because of the dates that our data were collected (qualitative data were obtained earlier than the quantitative outcome data). Lastly, because it is common in the measurement of any relatively new and rather complex construct, our faultline measure may have certain methodological limitations; for instance, it can be potentially sensitive to the statistical weighting processes. Future studies are needed to more accurately reflect the effects of faultlines and investigate how people perceive differences and make sense of them.

We believe our study has an advantage, however, over many archival studies, because we were able to obtain useful and relevant text data about the team, something most often missing in large archival data sets. Next, our study methodology is based on a combination of different methods (archival quantitative and qualitative data), and it is also less sensitive to commonmethod biases that are particularly problematic in survey research (Podsakoff et al. 2003). For instance, we designed our study and coding procedure (e.g., different raters who were unfamiliar to specific hypotheses performed the coding of different variables in our study) to eliminate the possibility for common variance due to method. As Podsakoff and colleagues (2003, p. 887) put it:

the advantage of this procedure is that it makes it impossible for the mind set of the source or rater to bias the observed relationship between the predictor and criterion variable, thus eliminating the effects of consistency motifs, implicit theories, social desirability tendencies, dispositional and transient mood states, and any tendencies on the part of the rater to acquiesce or respond in a lenient manner.

Research further suggests that common method variance does not bias in favor of interactions and is more problematic for the direct predictor-criterion relationships. For example, Evans (1985) concluded that commonmethod variance cannot generate artifactual interactions and may only serve to attenuate true interactions.

The results of this study also open the door for future research on faultlines in diverse workgroups. For example, past research has suggested looking at the mediating and moderating mechanisms as an alternative way of explaining the mixed effects of group diversity 
(cf. Williams and O'Reilly 1998). Lau and Murnighan (1998, p. 327) suggest that "faultlines have more potential for performance losses owing to increased subgroup conflict." One possibility for future research, therefore, would be to explore the effects of conflict in relation to the dynamics by which a group splits into subgroups when faultlines occur in diverse groups. Specifically, the examination of the mediating effects of three types of conflict-relationship, task, and process conflict (Jehn 1997, Jehn et al. 1999) — in the relationship between faultlines and performance may shed light on how a group-level construct affects both individuals and groups. For example, future research should examine how differences in groups with a subgroup-focused attitude may compare to groups with an entire-group focused attitude when examining performance. This may require collecting the data at different levels (e.g., subgroup versus group performance) in a laboratory setting because it might be a challenge for researchers to get measures of real subgroup performance in organizations. Although we do not specifically differentiate between these effects, given the focus of our paper, we believe that this is a very interesting topic that should be addressed in future studies.

Another line of research is to investigate the effects of other possible moderators and contextual factors, such as the organizational hierarchy or task interdependence. The alignment of members that are similar on social category (e.g., age and gender) or informational characteristics (e.g., tenure and education) can add to status effects and cause problems. For example, hierarchical power and status can accrue with age and gender, rendering the distance between younger female and older male subgroups to also be one of hierarchical power. ${ }^{2}$ Thus, an additional source of faultlines may be status within an organization. Certain groups may also have such strong faultlines with a large distance between subgroups that isolated, distinct groups may emerge, effectively cutting off contact between subgroups and triggering "exit dynamics" (Dyck and Starke 1999, Hart and Van Vugt 2006). Research on breakaway organizations and exit groups has led to a number of important insights, yet little is known about how the exit dynamics would unfold in common-goal organizational groups. Finally, future research should specifically examine the mechanisms behind potential and active group faultlines. Whereas potential faultlines are based on the objective demographics of group members, active group faultlines exist when the members perceive and behave as if there are two separate, different (and potentially even opposed) subgroups. Although objective demographic attributes may explain variance in perceptions and performance as we show in our study, we also believe that it is critical to examine what members themselves perceive to be a faultline, and when it is triggered, because this is the foundation for future interactions among group members.

\section{Implications for Managers}

The results of this study show that faultlines may not necessarily cause dysfunctional processes, as has been suggested in the past (e.g., Lau and Murnighan 1998, Thatcher et al. 2003), but rather may promote effective decision-making processes when members align along informational lines and have a strong superordinate team identity. Consequently, we provide evidence that the nature of alignment, and specifically the type of demographics responsible for the alignment (social category versus information-based), determines whether members of a group fully capitalize on their diversity. The delineation of the processes behind social category and information-based splits as provided by this research should help managers effectively handle the dynamics of diverse groups and maximize the productivity of their increasingly diverse workforce without being fearful of diversity. Based on our results, we suggest that managers should be aware of the potentially harmful effects of faultlines that divide groups along demographic lines. One way in which they may mitigate this risk would be to stress similarities across faultline divides and promote overall team identification. Strong identification with a group may consolidate group members around mutual goals and eventually facilitate group performance. In this sense, our extended faultline framework may provide a more comprehensive understanding of the functioning of diverse groups in organizational settings.

\section{Acknowledgments}

This research was supported by the Alfred P. Sloan Foundation, the SEI Center for Advanced Studies in Management of the Wharton School, and The George Harvey Program on Redefining Diversity: Value Creation Through Diversity. The authors would like to thank the M-squared working paper group of the Wharton School, University of Pennsylvania, for their helpful comments. In addition, they are very grateful to Madhan Gounder, Hina A Kharbey, Isaac O Choi, Apurva Dave, Andre Kursancew, and Vikas Keswani for their assistance in data analysis.

\section{Endnotes}

${ }^{1}$ Please note that whereas faultlines based on one characteristic are equally possible (Lau and Murnighan 2005, Molleman 2005), this study follows a theoretical approach that conceptualizes faultlines as based on multiple characteristics.

${ }^{2} \mathrm{We}$ would like to thank an anonymous reviewer for this comment.

\section{References}

Aiken, L. S., S. G. West. 1991. Multiple Regression: Testing and Interpreting Interactions. SAGE Publications, Inc., Newbury Park, CA.

Allison, P. D. 1978. Measures of inequality. Amer. Sociol. Rev. 43 $865-880$.

Ashforth, B. E., F. Mael. 1989. Social identity theory and the organization. Acad. Management Rev. 14 20-39. 
Barlow, M. 2000. Concordancing with MonoConc Pro. 2.0. Athelstan, Houston.

Bettencourt, B. A., K. E. Dill, S. Greathouse, K. Charlton, A. Mulholland. 1997. Evaluations of ingroup and outgroup members: The category-based expectancy violation. J. Experiment. Soc. Psych. 33 244-275.

Bezrukova, K., S. M. B. Thatcher, K. A. Jehn. 2007. Group heterogeneity and faultlines: Comparing alignment and dispersion theories of group composition. K. J. Behfar, L. L. Thompson, eds. Conflict in Organizational Groups: New Directions in Theory and Practice. Northwestern University Press, Evanston, IL, 57-92.

Blau, P. 1977. Inequality and Composition: A Primitive Theory of Social Structure. Free Press, New York.

Bliese, P. D. 2000. Within-group agreement, non-independence, and reliability: Implications for data aggregation and analysis. K. J. Klein, S. W. J. Kozlowski, eds. Multilevel Theory, Research, and Methods in Organizations. Jossey-Bass, San Francisco, 349-381.

Bogardus, E. S. 1925. Measuring social distances. J. Appl. Soc. 9 299-308.

Brewer, M. B. 1995. Managing diversity: The role of social identities. S. E. Jackson, M. N. Ruderman, eds. Diversity in Work Teams: Research Paradigms for a Changing Workplace. American Psychological Association, Washington, D.C., 47-68.

Brewer, M. B. 2000. Reducing prejudice through cross-categorization: Effects of multiple social identities. S. Oskamp, ed. Reducing Prejudice and Discrimination. Lawrence Erlbaum Associates, Mahwah, NJ, 165-183.

Brickson, S. L. 2005. Organizational identity orientation: Forging a link between organizational identity and organizations' relations with stakeholders. Admin. Sci. Quart. 50 576-609.

Chatman, J. A., F. J. Flynn. 2001. The influence of demographic heterogeneity on emergence and consequences of cooperative norms in work teams. Acad. Management J. 44 956-974.

Chatman, J. A., S. E. Spataro. 2005. Using self-categorization theory to understand relational demography-based variations in people's responsiveness to organizational culture. Acad. Management J. 48 321-331.

Clement, D., J. Schiereck. 1973. Sex composition and group performance in a visual signal detection task. Memory Cognition 1 251-255.

Cramton, C. D., P. J. Hinds. 2005. Subgroup dynamics in internationally distributed teams: Ethnocentrism or cross-national learning? B. Staw, R. Kramer, eds. Research in Organizational Behavior, Vol. 26. Elsevier Science Inc., Oxford, UK, 231-263.

Crisp, R. J., M. Hewstone. 2000. Crossed categorization and intergroup bias: The moderating roles of intergroup and affective context. J. Experiment. Soc. Psych. 36 357-383.

Cummings, A., J. Zhou, G. R. Oldham. 1993. Demographic differences and employees work outcomes: Effects of multiple comparison groups. Acad. Management Meetings, Atlanta, GA.

Dahlin, K. B., L. R. Weingart, P. J. Hinds. 2005. Team diversity and information use. Acad. Management J. 48 1107-1123.

De Dreu, C. K. W., M. A. West. 2001. Minority dissent and team innovation. J. Appl. Psych. 86 1191-1201.

Doucet, L., K. A. Jehn. 1997. Analyzing harsh words in a sensitive setting: American expatriates in communist China. J. Organ. Behav. 18 559-582.
Dovidio, J. F., S. L. Gaetner, A. Validzic. 1997a. Intergroup bias: Status, differentiation, and a common in-group identity. J. Personality Soc. Psych. 75 109-120.

Dovidio, J. F., S. L. Gaertner, A. Validzic, K. Matoka, B. Johnson, S. Frazier. 1997b. Extending the benefits of recategorization: Evaluations, self-disclosure, and helping. J. Experiment. Soc. Psych. 33 401-420.

Dyck, B., F. A. Starke. 1999. The formation of breakaway organizations: Observations and a process model. Admin. Sci. Quart. 44 792-822.

Earley, P. C., E. Mosakowski. 2000. Creating hybrid team cultures: An empirical test of transnational team functioning. Acad. Management J. 43 26-49.

Elvira, M. M., M. E. Graham. 2003. Not just a formality: Pay system formalization and the gender earnings effects. Organ. Sci. 13 601-617.

Ely, R. J., D. A. Thomas. 2001. Cultural diversity at work: The effects of diversity perspectives on work group processes and outcomes. Admin. Sci. Quart. 46 229-273.

Eurich-Fulcer, R., J. W. Schofield. 1995. Correlated versus uncorrelated social categorizations: The effect on intergroup bias. Personality Soc. Psych. Bull. 21 149-159.

Evans, M. G. 1985. A Monte Carlo study of the effects of correlated method variance in moderated multiple regression analysis. Organ. Behav. Human Decision Processes 36 305-323.

Florin, P., G. A. Giamartino, D. A. Kenny, A. Wandersman. 1990 Levels of analysis and effects: Clarifying group influence and climate by separating individual and group effects. J. Appl. Soc. Psych. 20 881-900.

Freidman, R. A., J. Podolny. 1992. Differentiation of boundary spanning roles: Labor negotiations and implications for role conflict. Admin. Sci. Quart. 37 28-47.

Gaertner, S. L., J. F. Dovidio. 2000. Reducing Intergroup Bias: The Common Ingroup Identity Model. Psychology Press/Taylor and Francis, Philadelphia.

Gaertner, S. L., J. F. Dovidio, P. A. Anastasio, B. A. Bachman, M. C. Rust. 1993. The common ingroup identity model: Recategorization and the reduction of integroup bias. W. Strobe, M. Hewstone, eds. The European Review of Social Psychology, Vol. 4. John Wiley \& Sons, London, 1-26.

Gibson, C., F. Vermeulen. 2003. A healthy divide: Subgroups as a stimulus for team learning behavior. Admin. Sci. Quart. 48 202-239.

Goodman, P. S., E. C. Ravlin, L. Argote. 1986. Current thinking about groups: Setting the stage for new ideas. P. Goodman, ed. Designing Effective Work Groups. Jossey-Bass, San Francisco, $1-33$.

Gruenfeld, D. H., E. A. Mannix, K. Y. Williams, M. A. Neale. 1996. Group composition and decision making: How member familiarity and information distribution affect process and performance. Organ. Behav. Human Decision Processes 67 1-15.

Hackman, J. R. 1987. The design of work teams. J. W. Lorsch, ed. Handbook of Organizational Behavior. Prentice-Hall, Englewood Cliffs, NJ, 315-342.

Hambrick, D. C., J. T. Li, K. Xin, A. S. Tsui. 2001. Compositional gaps and downward spirals in international joint venture management groups. Strategic Management J. 22 1033-1053.

Hart, C. M., M. Van Vugt. 2006. From faultlines to group fission: Understanding membership changes in small groups. Personality Soc. Psych. Bull. 32 392-404. 
Haslam, S. A., N. Ellemers. 2005. Social identity in industrial and organizational psychology: Concepts, controversies and contributions. Internat. Rev. Indust. Organ. Psych. 20 $39-118$.

Hewstone, M., M. Rubin, H. Willis. 2002. Intergroup bias. Annual Rev. Psych. 53 575-604.

Hogg, M. A., D. J. Terry. 2000. Social identity and social categorization processes in organizational contexts. Acad. Management Rev. 25 121-140.

Hornsey, M. J., M. A. Hogg. 2000. Subgroup relations: A comparison of mutual intergroup differentiation and common ingroup identity models of prejudice reduction. Personality Soc. Psych. Bull. 26 242-256.

Hraba, J., L. Hagendoorn, R. Hagendoorn. 1989. The ethnic hierarchy in the Netherlands: Social distance and social representation. British J. Soc. Psych. 28 57-69.

Jackson, S. E., A. Joshi, N. L. Erhardt. 2003. Recent research on teams and organizational diversity: SWOT analysis and implications. J. Management 29 801-830.

Jehn, K. A. 1997. A qualitative analysis of conflict types and dimensions in organizational groups. Admin. Sci. Quart. 42 520-557.

Jehn, K. A., O. Werner. 1993. Hapax Legomenon II: Theory, a thesaurus, and word frequency. Cultural Anthropology Method $\mathbf{5}$ $8-10$.

Jehn, K. A., K. Bezrukova, S. M. B. Thatcher. 2007. Conflict, diversity and faultlines in workgroups. C. K. W. De Dreu, M. Gelfand, eds. The Psychology of Conflict and Conflict Management in Organizations. The SIOP Frontiers Series, Lawrence Erlbaum, New York, 177-208.

Jehn, K. A., C. Chadwick, S. M. B. Thatcher. 1997. To agree or not to agree: The effects of value congruence, individual demographic dissimilarity and conflict on workgroup outcomes. Internat. J. Conflict Management 8 287-306.

Jehn, K. A., G. Northcraft, M. A. Neale. 1999. Why differences make a difference: A field study of diversity, conflict, and performance in workgroups. Admin. Sci. Quart. 44 741-763.

Jetten, J., R. Spears, A. S. R. Manstead. 1998. Defining dimensions of distinctiveness: Group variability makes a difference to differentiation. J. Personality Soc. Psych. 74 1481-1492.

Jetten, J., R. Spears, T. Postmes. 2004. Intergroup distinctiveness and differentiation: A meta-analytic integration. J. Personality Soc Psych. 86 862-879.

Jobson, J. D. 1992. Applied Multivariate Data Analysis. Volume II: Categorical and Multivariate Methods. Springer-Verlag, New York.

Kane, A. A., L. Argote, J. M. Levine. 2005. Knowledge transfer between groups via personnel rotation: Effects of social identity and knowledge quality. Organ. Behav. Human Decision Processes 96 56-71.

Lau, D., J. K. Murnighan. 1998. Demographic diversity and faultlines: The compositional dynamics of organizational groups. Acad. Management Rev. 23 325-340.

Lau, D., J. K. Murnighan. 2005. Interactions within groups and subgroups: The dynamic effects of demographic faultlines. Acad. Management J. 48 645-659.

Leong, C., C. Ward. 2000. Identity conflict in sojourners. Internat. J. Intercultural Relations 24 763-776.

Li, J. T., D. C. Hambrick. 2005. Factional groups: A new vantage on demographic faultlines, conflict, and disintegration in work teams. Acad. Management J. 48 794-813.
Mackie, D. M., T. Devos, E. R. Smith. 2000. Intergroup emotions: Explaining offensive action tendencies in an intergroup context. J. Personality Soc. Psych. 79 602-616.

Mael, F., B. E. Ashforth. 1992. Alumni and their alma mater: A partial test of the reformulated model of organizational identification. J. Organ. Behav. 13 103-123.

Mannix, E. A. 1993. Organizations as resource dilemmas: The effect of power balance on coalition formation in small groups. Organ Behav. Human Decision Processes 55 1-22.

Mannix, E. A., M. A. Neale. 2005. What differences make a difference? Psych. Sci. Public Interest 6 31-55.

Messick, D. M., D. M. Mackie. 1989. Intergroup relations. Annual Rev. Psych. 40 45-81.

Miller, D. T., D. A. Prentice. 1999. Some consequences of a belief in group essence: The category divide hypothesis. D. A. Prentice, D. T. Miller, eds. Cultural Divides: Understanding and Overcoming Group Conflict. Sage Publications, New York, 213-238.

Molleman, E. 2005. Diversity in demographic characteristics, abilities and personality traits: Do faultlines affect team functioning? Group Decision Negotiation 14 173-193.

Morrison, D. G. 1967. Measurement problems in cluster analysis Management Sci. 13 B-775-B-780.

Mottola, G. R., B. A. Bachman, S. L. Gaertner, J. F. Dovidio. 1997. How groups merge: The effects of merger integration patterns on anticipated commitment to the merged organization. $J$. Appl. Soc. Psych. 27 1335-1358.

Mullin, B. A., M. A. Hogg. 1998. Dimensions of subjective uncertainty in social identification and minimal intergroup discrimination. British J. Soc. Psych. 37 345-365.

Nemeth, C. J. 1986. Differential contributions of majority and minority influence. Psych. Rev. 93 23-32.

Nesdale, D., A. S. Mak. 2003. Ethnic identification, self-esteem, and immigrant psychological health. Internat. J. Intercultural Relations 27 23-40.

Pelled, L. H. 1996. Demographic diversity, conflict, work group outcomes: An intervening process theory. Organ. Sci. 7 615-631.

Pelled, L. H., K. M. Eisenhardt, K. R. Xin. 1999. Exploring the black box: An analysis of work group diversity, conflict and performance. Admin. Sci. Quart. 44 1-28.

Phillips, K. W. 2003. The effects of categorically based expectations on minority influence: The importance of congruence. Personality Soc. Psych. Bull. 29 3-13.

Podsakoff, P. M., S. B. MacKenzie, J. Lee, N. P. Podsakoff. 2003. Common method biases in behavioral research: A critical review of the literature and recommended remedies. J. Appl. Psych. $\mathbf{8 8}$ 879-903.

Polzer, J. T., L. P. Milton, W. B. Swann, Jr. 2002. Capitalizing on diversity: Interpersonal congruence in small work groups. Admin. Sci. Quart. 47 296-324.

Polzer, J. T., C. B. Crisp, S. L. Jarvenpaa, J. W. Kim. 2006. Extending the faultline model to geographically dispersed teams: How collocated subgroups can impair group functioning. Acad. Management J. 49 679-692.

Pratt, M. G. 1998. To be or not to be? Central questions in organizational identification. D. A. Whetten, P. C. Godfrey, eds. Iden tity in Organizations: Building Theory Through Conversations. SAGE Publications, Thousand Oaks, CA, 171-207. 
Pratt, M. G. 2000. The good, the bad, and the ambivalent: Managing identification among Amway distributors. Admin. Sci. Quart. 45 456-493.

Randel, A. E. 2002. Identity salience: A moderator of the relationship between group gender composition and work group conflict. J. Organ. Behav. 23 749-776.

Randel, A. E., K. S. Jaussi. 2003. Functional background identity, diversity, and individual performance in cross-functional teams. Acad. Management J. 46 763-774.

Rink, F., N. Ellemers. 2007. Diversity as a basis for shared organizational identity: The norm congruity principle. British J. Management 18 S17-S27.

Roccas, S., M. B. Brewer. 2002. Social identity complexity. Personality Soc. Rev. 6 88-106.

Rokeach, M. R. 1960. The Open and Closed Mind. Basic Books, New York.

Salk, J. E., O. Shenkar. 2001. Social identities in an international joint venture: An exploratory case study. Organ. Sci. 12 161-178.

Sawyer, J. E., M. A. Houlette, E. L. Yealey. 2006. Decision performance and diversity structure: Comparing faultlines in convergent, crosscut, and racially homogeneous groups. Organ. Behav. Human Decision Processes 99 1-15.

Schweiger, D. M., W. R. Sandberg. 1989. The utilization of individual capabilities in group approaches to strategic decision-making. Strategic Management J. 10 31-44.

Schwenk, C. R. 1990. Effects of devil's advocacy and dialectical inquiry on decision making: A meta-analysis. Organ. Behav. Human Decision Processes 47 161-176.

Sharma, S. 1996. Applied Multivariate Techniques. John Wiley and Sons, New York.

Sherif, M. 1966. Group Conflict and Cooperation. Routledge, London.

Stevenson, W. B., J. L. Pearce, L. W. Porter. 1985. The concept of "coalition" in organizational theory and research. Acad. Management Rev. 10 256-268.

Tafarodi, R. W., S. Kang, A. B. Milne. 2002. When different becomes similar: Compensatory conformity in bicultural visible minorities. Personality Soc. Psych. Bull. 28 1131-1142.

Tajfel, H., J. C. Turner. 1986. The social identity theory of intergroup behavior. S. Worchel, W. G. Austin, eds. Psychology of Intergroup Relations. Nelson-Hall, Chicago, 7-24.
Thatcher, S. M. B., K. A. Jehn, E. Zanutto. 2003. Cracks in diversity research: The effects of faultlines on conflict and performance. Group Decision Negotiation 12 217-241.

Tsui, A. S., T. D. Egan, C. A. O'Reilly. 1992. Being different: Relational demography and organizational attachment. Admin. Sci. Quart. 37 549-577.

Tziner, A., D. Eden. 1985. Effects of crew composition on crew performance: Does the whole equal the sum of its parts? J. Appl. Psych. 70 85-94.

Van de Ven, A. H., A. L. Delbecq, R. Koenig, Jr. 1976. Determinants of coordination modes within organizations. Amer. Soc. Rev. 41 $322-338$.

Van der Vegt, G. S., J. S. Bunderson. 2005. Learning and performance in multi-disciplinary teams: The importance of collective team identification. Acad. Management J. 48 532-547.

Van Knippenberg, D., N. Ellemers. 2003. Social identity and group performance: Identification as the key to group-oriented effort. S. A. Haslam, D. van Knippenberg, M. J. Platow, N. Ellemers, eds. Social Identity at Work: Developing Theory for Organizational Practice. Psychology Press, New York, 29-42.

Van Knippenberg, D., M. C. Schippers. 2007. Work group diversity. Annual Rev. Psychol. 58 515-541.

Van Vugt, M., C. M. Hart. 2004. Social identity as social glue: The origins of group loyalty. J. Personality Soc. Psych. 86 585-598.

Wagner, W. G., J. Pfeffer, C. A. O’Reilly. 1984. Organizational demography and turnover in top management groups. Admin. Sci. Quart. 29 74-92.

Watson, W. E., K. Kumar, L. K. Michaelson. 1993. Cultural diversity's impact on interaction process and performance: Comparing homogeneous and diverse task groups. Acad. Management J. 38 590-602.

Webber, S., L. Donahue. 2001. Impact of highly and less jobrelated diversity on work group cohesion and performance: A meta-analysis. J. Management 27 141-162.

Weber, R. A., C. F. Camerer. 2003. Cultural conflict and merger failure: An experimental approach. Management Sci. 49 400-415.

Williams, K., C. A. O'Reilly. 1998. Demography and diversity in organizations: A review of 40 years of research. B. M. Staw, L. L. Cummings, eds. Research in Organizational Behavior, Vol. 20. Elsevier Science Inc., Oxford, UK, 77-140. 